This is the accepted manuscript made available via CHORUS, the article has been published as:

\title{
Compensation in Al-Doped ZnO by Al-Related Acceptor Complexes: Synchrotron X-Ray Absorption Spectroscopy and Theory
}

J. T-Thienprasert, S. Rujirawat, W. Klysubun, J. N. Duenow, T. J. Coutts, S. B. Zhang, D. C. Look, and S. Limpijumnong

Phys. Rev. Lett. 110, 055502 - Published 28 January 2013

DOI: 10.1103/PhysRevLett.110.055502 


\section{Compensation in Al-doped $\mathrm{ZnO}$ by Al-related acceptor complexes: synchrotron $x$-ray absorption spectroscopy and theory}

J. T-Thienprasert, ${ }^{1,2}$ S. Rujirawat, ${ }^{3}$ W. Klysubun, ${ }^{4}$ J.N. Duenow, ${ }^{5}$ T.J. Coutts, ${ }^{5}$ S.B. Zhang, ${ }^{6}$ D.C. Look, ${ }^{7}$ and S. Limpijumnong ${ }^{3}$

${ }^{1}$ Department of Physics, Kasetsart University, Bangkok 10900, Thailand

${ }^{2}$ Thailand Center of Excellence in Physics (ThEP Center), Commission on Higher Education, Bangkok 10400, Thailand

${ }^{3}$ School of Physics, Suranaree University of Technology, Nakhon Ratchasima 30000, Thailand

${ }^{4}$ Synchrotron Light Research Institute, Nakhon Ratchasima 30000, Thailand

${ }^{5}$ National Renewable Energy Laboratory, Golden, Colorado 80401, USA

${ }^{6}$ Physics Department, Rensselaer Polytechnic Institute, Troy, New York 12180, USA

${ }^{7}$ Semiconductor Research Center, Wright State University, Dayton, Ohio 45435, USA

\section{Abstract}

Synchrotron x-ray absorption near edge structures (XANES) technique was used in conjunction with first-principles calculations to characterize Al-doped $\mathrm{ZnO}$ films. Standard characterizations revealed that the amount of carrier concentration and mobility depend on the growth conditions, i.e. $\mathrm{H}_{2}\left(\right.$ or $\left.\mathrm{O}_{2}\right) / \mathrm{Ar}$ gas ratio and $\mathrm{Al}$ concentration. First-principles calculations showed that Al energetically prefers to substitute on the $\mathrm{Zn}$ site, forming a donor $\mathrm{Al}_{\mathrm{Zn}}$, over being an interstitial $\left(\mathrm{Al}_{i}\right)$. The measured $\mathrm{Al} K$-edge XANES spectra are in good agreement with the simulated spectra of $\mathrm{Al}_{\mathrm{Zn}}$, indicating that majority of $\mathrm{Al}$ atoms are substituting for $\mathrm{Zn}$. The reduction in carrier concentration or mobility in some samples can be attributed to the $\mathrm{Al}_{\mathrm{Zn}}-V_{\mathrm{Zn}}$ and $2 \mathrm{Al}_{\mathrm{Zn}}-V_{\mathrm{Zn}}$ complex formations that have similar XANES features. In addition, XANES of some samples showed additional features that are the indication of some $\alpha-\mathrm{Al}_{2} \mathrm{O}_{3}$ or $n \mathrm{Al}_{\mathrm{Zn}}-\mathrm{O}_{i}$ formation; explaining their poorer conductivity.

Keyword 
Transparent conductive oxides (TCOs) are needed in many applications, for instance, touch screens, solar cells and photovoltaic devices.[1-3] The most commonly used TCO is indium tin oxide. Recently, $\mathrm{ZnO}$ has been extensively studied for its TCO aspects, in hope to replace indium tin oxide, because it is nontoxic, low-cost, and abundant. As-grown $\mathrm{ZnO}$ is an $n$-type wide band gap $(\sim 3.3$ $\mathrm{eV})$ semiconductor where its conductivity is believed to originate mainly from the intrinsic defects or unintentional hydrogen impurity [4-6]. Native defects and unintentional impurities in $\mathrm{ZnO}$ have also been studied theoretically.[6-9] A highly conductive $\mathrm{ZnO}$ thin film with high transmittance in the visible light region can be achieved by doping with group-III elements. Among group-III doped ZnO, Al-doped $\mathrm{ZnO}(\mathrm{AZO})$ emerged as the most promising candidate due to its high temperature stability and the fact that $\mathrm{Al}$ is abundant. There are several deposition techniques that have been reported to successfully produce AZO thin films. These include chemical vapor deposition (CVD),[10] magnetron sputtering,[11] spray pyrolysis,[12] and pulsed laser deposition (PLD).[13]

Partial information on how during-growth and post-growth conditions (such as oxygen partial pressure and ultraviolet-ozone treatment) affect AZO film quality is reported.[1, 13] However, none of the previous study offers the detailed information on the local structure of $\mathrm{Al}$ site in $\mathrm{ZnO}$ crystal. In this letter, a combination of $\mathrm{Al} \mathrm{K}$ edge x-ray absorption near edge structures (XANES) and first-principles calculations was used to investigate the rf-magnetron sputtered AZO films grown under different conditions $\left(\mathrm{H}_{2} / \mathrm{Ar}\right.$ or $\mathrm{O}_{2} / \mathrm{Ar}$ gas $)$ and with different $\mathrm{Al}$ concentrations. This work illustrates that the combined systematic XANES measurements and first principles calculations can be used to identify the local structures of impurities which should have broad applications for many systems. 
AZO films were grown by rf-magnetron sputtering using oxide target with Argon as the primary sputtering gas. To manipulate the growth condition (O-rich or O-poor), small amounts of $\mathrm{O}_{2}$ or $\mathrm{H}_{2}$ were added to the Ar at different ratios. All films were deposited on Corning glass (7059 or 1737) with the substrate temperature of $200^{\circ} \mathrm{C}$. The carrier concentration and mobility of the films were measured with the detail described in Ref. [14].

To study the effects of $\mathrm{Al}$ content, we examined four films grown with varied Al content from 0.1 to 2.0 wt. $\%$. The weight percents were calculated from the weight of $\mathrm{Al}_{2} \mathrm{O}_{3}$ versus $\mathrm{ZnO}$ in the starting material. The sputtering gas was fixed at the $\mathrm{H}_{2} /$ Ar gas ratio of $0.3 \%$. The concentration and mobility are shown in Table I and Fig. 1. The Al content is labeled at the end of the sample name. As the Al content increased by 20 times, i.e. from $0.1 \%$ to $2.0 \%$, the carrier concentration increased but by only 7 times, i.e. from $1.1 \times 10^{20} \mathrm{~cm}^{-3}$ to $7.3 \times 10^{20} \mathrm{~cm}^{-3}$ accompanied by the reduction in electron mobility by about half, i.e. from 52 to $25 \mathrm{~cm}^{2} \mathrm{~V}^{-1} \mathrm{~s}^{-1}$.

To study the effects of growth condition, we fixed the Al content at $1.0 \mathrm{wt} . \%$ and examined five samples that were grown with varied sputtering gas ratios, starting from $\mathrm{O}_{2}$-rich $\left(\mathrm{O}_{2} / \mathrm{Ar}=0.5 \%\right)$ to pure $\mathrm{Ar}$ to $\mathrm{O}_{2}$-poor $\left(\mathrm{H}_{2} / \mathrm{Ar}=1 \%\right) ; \mathrm{H}_{2}$ is used to suppress $\mathrm{O}_{2}$ released from the sputtering target. The sample names are label to reflect these sputtering gas ratios, i.e., $\mathrm{OP}=\mathrm{O}$-poor, $\mathrm{OR}=\mathrm{O}$-rich, and $\mathrm{OFix}=$ pure Ar. It was found that the carrier concentration increased by nearly two orders of magnitude, i.e. from $7.3 \times 10^{18} \mathrm{~cm}^{-3}$ to $5.7 \times 10^{20} \mathrm{~cm}^{-3}$ as the sputtering gas changed from $\mathrm{O}_{2}$-rich to O-poor condition. The mobility was near zero under the O-rich condition and rapidly increased under pure $\mathrm{Ar}$ and $\mathrm{H}_{2} / \mathrm{Ar}$ conditions with the highest value taken place when the sputtering gas contained $0.3 \% \mathrm{H}_{2} / \mathrm{Ar}$ ratio (labeled OP-a). 
All of the films were characterized by x-ray absorption measurements in the fluorescent mode with a 13-component Ge detector (Canbera) at beamline \#8 of the Siam Photon Source (electron energy of $1.2 \mathrm{GeV}$, beam current $80-120 \mathrm{~mA}$ ) of the Synchrotron Light Research Institute, Thailand [15]. A double crystal monochromator $\mathrm{KTiOPO}_{4}$ was used to scan the synchrotron x-ray with the photon energy step of $0.25 \mathrm{eV}$ in the range of 1550 to $1610 \mathrm{eV}$, covering the XANES region of Al $K$-edge. The measured spectra are shown in Fig. 2(a) and 2(b). In general, all measured spectra composed of two peaks; labeled P1 and P2.

In order to relate the observed spectra to the local structure around $\mathrm{Al}$ atom, we performed first principles calculations.[16] Two computational codes, i.e., the Vienna ab initio simulation package (VASP) $[17,18]$ and the FEFF8.2 codes[19, 20], were employed in series. The VASP codes were used to optimize the detailed relaxation of the defect structures as well as to determine their energetic stability. The FEFF8.2 codes were used to simulate the XANES spectra from the relaxed local structures obtained from VASP. In VASP calculations, the density functional theory (DFT) within the local density approximation (LDA) for the exchange-correction functional was used. The atomic potentials used in these calculations were the ultrasoft pseudopotential with projector-augmented wave (PAW)[21], allowing a rather low energy cutoff of $500 \mathrm{eV}$ for the plane-wave basis set. The calculated lattice parameters of bulk $\mathrm{ZnO}$ are $a=3.21$ and $c / a=1.61 \AA$, which are in good agreement with the experimental values of $a=3.25$ and $c / a=1.60 \AA$. [22] To study defects, we used the supercell approach with a 96-atom supercell. The Monkhorst-Pack scheme[23] with a shifted sampling mesh of $2 \times 2 \times 2$ was used for $k$-space integrations. All atoms in the supercell were allowed to relax until the HellmannFeynman[24] forces become less than $10^{-3} \mathrm{eV} / \AA$. After the optimized structures were 
obtained, the coordinates were ported into the FEFF8.2 code for XANES spectra simulation. The FEFF8.2 code is based on the multiple-scattering expansion with the muffin-tin potentials. The Hedin-Lundqvist was used as the exchange potential with an imaginary part of $0.5 \mathrm{eV}$ to simulate the experimental broadening. The radii of self-consistent muffin-tin atomic potential and full-multiple scattering were set at 0.55 $\mathrm{nm}$ and $0.80 \mathrm{~nm}$, respectively.

The obvious choices for the possible forms of $\mathrm{Al}$ in $\mathrm{ZnO}$ are $\mathrm{Al}$ substitution for $\mathrm{Zn}\left(\mathrm{Al}_{\mathrm{Zn}}\right)$, phase separated $\alpha-\mathrm{Al}_{2} \mathrm{O}_{3}$ and metal Al. These crystal structures were first calculated and optimized using the VASP codes. After that, the corresponding XANES spectra [Fig. 2(c)] were simulated using the FEFF8.2 codes. The simulated spectrum of $\mathrm{Al}_{\mathrm{Zn}}$ contains two peaks that are consistent with $\mathrm{P} 1$ and $\mathrm{P} 2$ observed in the $\mathrm{Al}$ doped $\mathrm{ZnO}$ samples. On the other hand, the simulated spectrum of $\alpha-\mathrm{Al}_{2} \mathrm{O}_{3}$ contains only one large broad peak at the energy near the P1 peak and that of metal Al has broad features without any sharp peak. Among three spectra, it is clear that only the simulated XANES spectrum of $\mathrm{Al}_{Z \mathrm{n}}$ has overall feature consistent with the measured XANES spectra. To understand the source of the differences between the two-peak (P1 and $\mathrm{P} 2$ ) feature in $\mathrm{Al}_{\mathrm{Zn}}$ spectrum and the single broad peak feature in $\alpha$ $\mathrm{Al}_{2} \mathrm{O}_{3}$ spectrum, we investigated the electronic states associated with them. The siteprojected partial density of unoccupied $p$-states (PDOS) plots around the Al atom, based on VASP calculations (following Ref. [25] which describes the case of Mn in $\mathrm{PbTiO}_{3}$ ), of $\mathrm{Al}_{\mathrm{Zn}}$ in $\mathrm{ZnO}$ and $\alpha-\mathrm{Al}_{2} \mathrm{O}_{3}$ are shown in Fig. 3 (a) and 3 (b), respectively. For $\mathrm{Al}_{\mathrm{Zn}}$, the unoccupied $p$-states around the four-fold $\mathrm{Al}$ atom can be split into two groups, the lower energy (P1) and the higher energy (P2) ones. The charge density plot shows that the lower energy group of states is localized in the region away from the Al-O bonds while the higher energy group of states is localized closer to the 
bonds. On the other hand, for the six-fold $\mathrm{Al}$ in $\mathrm{Al}_{2} \mathrm{O}_{3}$, the unoccupied $p$-states are more symmetric and are localized away from the bonds without the group of higher energy ones.

Figure 2(a) shows the measured spectra of the samples with varied Al content from 0.1 to $2.0 \%$. The $\mathrm{P} 1$ peak is the sharpest for $0.1 \%$ sample and becomes broader in samples with higher $\mathrm{Al}$ content. The broadening of the $\mathrm{P} 1$ peak as $\mathrm{Al}$ content increase is an indication of the second form of $\mathrm{Al}$ in addition to $\mathrm{Al}_{\mathrm{Zn}}$. The most probable candidates are $\mathrm{Al}_{2} \mathrm{O}_{3}$ and $n \mathrm{Al}_{\mathrm{Zn}}-\mathrm{O}_{i}(n=1$ or 2$)$ complexes in $\mathrm{ZnO}$ where their main features contain a broader peak centering near P1 as shown in Fig. 2(c). The formation of the phase separated $\mathrm{Al}_{2} \mathrm{O}_{3}$ or $n \mathrm{Al}_{\mathrm{Zn}}-\mathrm{O}_{i}$ (poorer crystal quality) is consistent with the observed lower carrier mobility as the Al content increase. The formation of unwanted $\mathrm{Al}_{2} \mathrm{O}_{3}$ or $n \mathrm{Al}_{\mathrm{Zn}}-\mathrm{O}_{i}$, which competes the formation of the desired $\mathrm{Al}_{\mathrm{Zn}}$, explains why the carrier concentration increases by only 7 times as the Al concentration increases by 20 times.

Figure 2(b) shows the measured spectra of the samples grown with $1.0 \% \mathrm{Al}$ content but with different sputtered gas conditions, from O-rich to O-poor. The P1 peaks of all samples are broad (slightly sharper for the samples grown under O-rich conditions), suggesting that the samples contain $\mathrm{Al}_{\mathrm{Zn}}$ with a small amount of $\mathrm{Al}_{2} \mathrm{O}_{3}$ (or $n \mathrm{Al}_{\mathrm{Zn}}-\mathrm{O}_{i}$ ). The spectra from samples with different sputtered gas conditions are quite similar; suggesting similar fraction of phase separated $\mathrm{Al}_{2} \mathrm{O}_{3}$ (or $n \mathrm{Al}_{\mathrm{Zn}}-\mathrm{O}_{i}$ ). However, the carrier concentration and mobility are greatly varied with the sputtered gas condition. The variation of the carrier concentration and mobility indicates the formation of defect complexes between $\mathrm{Al}_{\mathrm{Zn}}$ and native defect(s) or the passivation of $\mathrm{Al}_{\mathrm{Zn}}$ by native defect(s). For example, a deep double acceptor $\mathrm{Zn}$ vacancy $\left(V_{\mathrm{Zn}}\right)$ can 
bind with $\mathrm{Al}_{\mathrm{Zn}}$ forming either $\mathrm{Al}_{\mathrm{Zn}}-V_{\mathrm{Zn}}$ (single acceptor) or $2 \mathrm{Al}_{\mathrm{Zn}}-V_{\mathrm{Zn}}$ (neutral) defect complexes.

To evaluate the formation nature of defects and defect complexes under different growth conditions, we calculated the formation energy of each defect defined [26] as

$$
\Delta H_{f}=E_{\mathrm{tot}}\left(D^{q}\right)-E_{\mathrm{tot}}(0)-\sum \Delta n_{x} \mu_{x}+q\left(E_{f}+E_{v}\right)
$$

where $E_{\text {tot }}\left(D^{q}\right)$ is the calculated total energy of a supercell containing a defect $D$ in charge state $q, E_{\text {tot }}(0)$ is the calculated total energy of the same supercell without a defect, $\Delta n_{x}$ is the number of atoms from species $X(=\mathrm{Zn}, \mathrm{O}$, or $\mathrm{Al})$ being added to (negative sign $=$ removed from) a supercell to form the defect cell. $\mu_{x}$ is the reservoir chemical potential of specie $X, E_{f}$ is the electron Fermi energy, and $E_{v}$ is the valence band maximum (VBM) of $\mathrm{ZnO}$ (here, we adopted the approach used in Ref. [26] for the VBM determination as well as the energy alignment between the defect supercell and defect-free supercell). Although DFT-LDA calculations strongly underestimated bulk $\mathrm{ZnO}$ bandgap $\left(E_{g, \mathrm{LDA}}=0.9 \mathrm{eV}\right)$, test calculations using hybrid-functional approach shows that our calculated formation energies remain accurate to within 0.2 $\mathrm{eV}$ and the main conclusion drawn in this work is not affected by the band gap underestimation [27].

The upper limits for $\mu_{\mathrm{Zn}}, \mu_{\mathrm{O}}$, and $\mu_{\mathrm{Al}}$ are the energies of solid $\mathrm{Zn}$, gaseous $\mathrm{O}_{2}$, and solid $\mathrm{Al}$, which we referenced as the zero point. To grow $\mathrm{ZnO}$ in equilibrium, it is required that $\mu_{\mathrm{Zn}}+\mu_{\mathrm{O}}=\mu_{\mathrm{ZnO}}$, where the calculated $\mathrm{ZnO}$ heat of formation; $\mu_{\mathrm{ZnO}}=-3.53 \mathrm{eV}$. Therefore, in our calculations, we have $\mu_{\mathrm{Zn}}=-3.53 \mathrm{eV}-\mu_{\mathrm{O}}$ where $-3.53 \mathrm{eV} \leq \mu_{\mathrm{O}} \leq 0$ (note that $\mu_{\mathrm{O}}=0$ defined as half of the $\mathrm{O}_{2}$ energy). In the presence of $\mathrm{O}, \mathrm{Al}$ prefers to form $\mathrm{Al}_{2} \mathrm{O}_{3}$ over solid $\mathrm{Al}$. Therefore, the upper limit of 
$\mu_{\mathrm{Al}}$ is set by $\mathrm{Al}_{2} \mathrm{O}_{3}$ precipitation limits, i.e. $\mu_{\mathrm{Al}}^{\max }=\left[\mu_{\mathrm{Al}_{2} \mathrm{O}_{3}}-3 \mu_{\mathrm{O}}\right] / 2$. For zinc-rich condition $\left(\mu_{\mathrm{Zn}}=0\right), \quad \mu_{\mathrm{Al}}^{\max }=-3.44 \mathrm{eV} . \quad$ For oxygen-rich condition $\left(\mu_{\mathrm{O}}=0\right)$, $\mu_{\mathrm{Al}}^{\max }=-8.73 \mathrm{eV}$

The calculated total energies are shown in detail as an auxiliary document [27]. The calculations show that $\mathrm{Al}_{\mathrm{Zn}}$ is a single shallow donor without the transition energy in the gap. Zn vacancy $\left(V_{\mathrm{Zn}}\right)$ is an acceptor with two transition energies at $\varepsilon(0 / 1-)=0.09 \mathrm{eV}$ and $\varepsilon(1-/ 2-)=0.38 \mathrm{eV}$. O interstitial $\left(\mathrm{O}_{i}\right)$ is a deeper acceptor with two transition energies at $\varepsilon(0 / 1-)=0.27 \mathrm{eV}$ and $\varepsilon(1-/ 2-)=0.87 \mathrm{eV}$.

Under $\mathrm{Zn}$-rich condition, the formation energy of $\mathrm{Al}_{\mathrm{Zn}}$ is the lowest one for semi-insulating to n-type samples, i.e., when the Fermi energy is in the range from around mid gap to the conduction band minimum. The formation energy of the interstitial $\mathrm{Al}\left(\mathrm{Al}_{i}\right)$ is several $\mathrm{eV}$ higher than $\mathrm{Al}_{\mathrm{Zn}}$ under this condition (See Ref. [27]). Therefore, the $\mathrm{Al}_{\mathrm{Zn}}$ donor is expected to be the dominant defect form. Because the formation energies of $V_{\mathrm{Zn}}$ and $\mathrm{O}_{i}$ that are native acceptors are high in this growth condition, they would not form in a significant amount and the sample would remain in a good $n$-type condition. Interestingly, $\mathrm{Al}_{\mathrm{Zn}}$ formation energy is lower under $\mathrm{Zn}$ rich condition than under O-rich condition. This is quite counter-intuitive because generally one would expect the Al to have the best chance to substitute for $\mathrm{Zn}$ site when there is less $\mathrm{Zn}$ to compete with, i.e., Zn-poor condition. However, for this particular case, the chemical potential of $\mathrm{Al}$ is limited by the $\mathrm{O}$ chemical potential due to $\mathrm{Al}_{2} \mathrm{O}_{3}$ precipitation limit. The highest possible $\mu_{\mathrm{Al}}$ requires the lowest $\mu_{\mathrm{O}}$, i.e., $\mathrm{Zn}$ rich condition.

Under O-rich condition, the formation energy of $\mathrm{Al}_{\mathrm{Zn}}$ is higher than the native acceptors $V_{\mathrm{Zn}}$ and $\mathrm{O}_{i}$ under $n$-type conditions (high Fermi energy). As a result, $V_{\mathrm{Zn}}$ 
and $\mathrm{O}_{i}$ could form and either compensate or passivate $\mathrm{Al}_{\mathrm{Zn}}$ leading to lower $n$-type conductivity. Because $V_{\mathrm{Zn}}$ has lower formation energy, it is more likely to form than $\mathrm{O}_{i}$

When co-existed, $\mathrm{Al}_{\mathrm{Zn}}$ and $V_{\mathrm{Zn}}$ can form complexes defect via the following reactions,

$$
\begin{gathered}
\mathrm{Al}_{\mathrm{Zn}}^{+}+V_{\mathrm{Zn}}^{2-} \rightarrow\left(\mathrm{Al}_{\mathrm{Zn}}-V_{\mathrm{Zn}}\right)^{1-} \\
\mathrm{Al}_{\mathrm{Zn}}^{+}+\mathrm{Al}_{\mathrm{Zn}}^{+}+V_{\mathrm{Zn}}^{2-} \rightarrow\left(2 \mathrm{Al}_{\mathrm{Zn}}-V_{\mathrm{Zn}}\right) .
\end{gathered}
$$

Equations (1) and (2) are exothermic with binding energies 0.53 and $1.19 \mathrm{eV}$, respectively, assuming the Fermi energy is at the conduction band minimum. This binding energies give the maximum passivation efficiency, $\kappa_{D}^{\max }$, defined in Ref. [28], of about 0.9 (calculated using the growth temperature of $200{ }^{\circ} \mathrm{C}$ ), suggesting that the complex could potentially form. The $\mathrm{Al}_{\mathrm{Zn}}-V_{\mathrm{Zn}}$ complex is a deep acceptor with the transition energy at $\varepsilon(0 / 1-)=0.39 \mathrm{eV}$. On the other hand, the $2 \mathrm{Al}_{\mathrm{Zn}}-V_{\mathrm{Zn}}$ complex is neutral. In a similarly manner, $\mathrm{Al}_{\mathrm{Zn}}$ and $\mathrm{O}_{i}$ can form an electrically amphoteric $\mathrm{Al}_{\mathrm{Zn}}-\mathrm{O}_{i}$ complex with the transition energy at $\varepsilon(1+/ 1-)=0.72 \mathrm{eV} . \quad \mathrm{Al}_{\mathrm{Zn}}-\mathrm{O}_{i}$ can further bind another $\mathrm{Al}_{\mathrm{Zn}}$ and form $2 \mathrm{Al}_{\mathrm{Zn}}-\mathrm{O}_{i}$ complex, which is neutral. The binding energy of $\mathrm{Al}_{\mathrm{Zn}}-\mathrm{O}_{i}$ and $2 \mathrm{Al}_{\mathrm{Zn}}-\mathrm{O}_{i}$ are as large as 1 and $2 \mathrm{eV}$, respectively (depending on the Fermi energy, See Ref. [27]). The formation of these $\mathrm{Al}_{\mathrm{Zn}}-V_{\mathrm{Zn}}$ and $\mathrm{Al}_{\mathrm{Zn}}-\mathrm{O}_{i}$ complex defects would suppress the $n$-type carriers leading to poorer $n$-type conductivity.

Because the above mentioned complexes, i.e., $\mathrm{Al}_{\mathrm{Zn}}-V_{\mathrm{Zn}}, 2 \mathrm{Al}_{\mathrm{Zn}}-V_{\mathrm{Zn}}, \mathrm{Al}_{\mathrm{Zn}}-\mathrm{O}_{i}$, and $2 \mathrm{Al}_{\mathrm{Zn}}-\mathrm{O}_{i}$ are bound and can potentially be formed, we simulated their XANES spectra [also shown in Fig. 2(c)]. The XANES spectra of $\mathrm{Al}_{\mathrm{Zn}}-V_{\mathrm{Zn}}$ and $2 \mathrm{Al}_{\mathrm{Zn}}-V_{\mathrm{Zn}}$ complexes are very similar to that of $\mathrm{Al}_{\mathrm{Zn}}$ since the vacancies are the second 
neighbors to the $\mathrm{Al}_{\mathrm{Zn}}$ and the local structure of the $\mathrm{Al}$ atom remains four-folded. On the other hand, the XANES spectra of $\mathrm{Al}_{\mathrm{Zn}}-\mathrm{O}_{i}$ and $2 \mathrm{Al}_{\mathrm{Zn}}-\mathrm{O}_{i}$ complexes are quite distinct from that of $\mathrm{Al}_{\mathrm{Zn}}$. The $\mathrm{O}$ interstitial is situated next to $\mathrm{Al}_{\mathrm{Zn}}$, increasing the coordination of the $\mathrm{Al}$ atom to five. The increase in coordination number limits the split of the unoccupied $p$-states around the Al atom in a similar way as the six-fold Al in $\alpha-\mathrm{Al}_{2} \mathrm{O}_{3}$. As a result, the XANES spectra of $\mathrm{Al}_{\mathrm{Zn}}-\mathrm{O}_{i}$ and $2 \mathrm{Al}_{\mathrm{Zn}}-\mathrm{O}_{i}$ complexes contain one large broad low-energy peak similar to the spectrum of $\alpha-\mathrm{Al}_{2} \mathrm{O}_{3}$ and a much reduced $\mathrm{P} 2$ peak.

The formation energy calculations and XANES simulations show that (1) Znrich condition is the most favorable condition for $\mathrm{Al}_{\mathrm{Zn}}$ to form. (2) Under O-rich conditions, native acceptor defects $V_{\mathrm{Zn}}$ and $\mathrm{O}_{i}$ have low energy and can either compensate or passivate $\mathrm{Al}_{\mathrm{Zn}}$ (forming $n \mathrm{Al}_{\mathrm{Zn}}-V_{\mathrm{Zn}}$ or $n \mathrm{Al}_{\mathrm{Zn}}-\mathrm{O}_{i}$ complexes) reducing the conductivity and mobility of the sample. (3) The simulated XANES spectra of $n \mathrm{Al}_{\mathrm{Zn}^{-}}$ $V_{\mathrm{Zn}}$ is almost identical to that of $\mathrm{Al}_{\mathrm{Zn}}$. This explains why samples grown under O-rich conditions can have similar XANES spectra to those grown under O-poor conditions despite its much lower values of mobility and conductivity. (4) The simulated XANES spectra of $n \mathrm{Al}_{\mathrm{Zn}}-\mathrm{O}_{i}$, which has five-folded $\mathrm{Al}$, is similar that of $\alpha-\mathrm{Al}_{2} \mathrm{O}_{3}$ (sixfold). This shows that the broadening of the first peak in some samples is the indicator of the higher coordinated $\mathrm{Al}$ that can be either phase separated $\alpha-\mathrm{Al}_{2} \mathrm{O}_{3}$ or defect complexes such as $n \mathrm{Al}_{\mathrm{Zn}}-\mathrm{O}_{i}$ both of which lead to lower conductivity and mobility.

In summary, Al-doped $\mathrm{ZnO}$ thin films prepared by rf magnetron sputtering under different growth conditions and $\mathrm{Al}$ contents were studied by $\mathrm{Al} K$-edge x-ray absorption spectroscopy in the near edge region (XANES). First principles total energy calculations and XANES simulations were employed to relate the measured 
results to the local atomic structures. The formation energy of $\mathrm{Al}_{\mathrm{Zn}}$ is the lowest under $\mathrm{Zn}$-rich conditions in agreement with the experimental observation that a better n-type Al-doped $\mathrm{ZnO}$ film is grown under Zn-rich conditions. The measured XANES spectra consist of two peaks in agreement with the simulation of $\mathrm{Al}_{\mathrm{Zn}}$ spectrum. In films with higher $\mathrm{Al}$ contents the low energy peak is broadening which could be the indication of some phase separated $\alpha-\mathrm{Al}_{2} \mathrm{O}_{3}$ or $n \mathrm{Al}_{\mathrm{Zn}}-\mathrm{O}_{i}$ complex formation. For films grown under O-rich conditions, the poorer $n$-type conductivity could be attributed to the formation of $n \mathrm{Al}_{\mathrm{Zn}}-\mathrm{V}_{\mathrm{Zn}}$ complexes which are not donors and have almost identical XANES spectrum to that of $\mathrm{Al}_{\mathrm{Zn}}$. 


\section{Reference}

[1] G. B. Murdoch et al., Applied Physics Letters 94, 213301 (2009).

[2] G. K. R. Senadeera et al., Applied Physics Letters 83, 5470 (2003).

[3] K. Tonooka, H. Bando, and Y. Aiura, Thin Solid Films 445, 327 (2003).

[4] D. C. Reynolds et al., Solid State Communications 101, 643 (1997).

[5] D. C. Look, Materials Science and Engineering: B 80, 383 (2001).

[6] A. Janotti, and C. G. Van de Walle, Physical Review B 76, 165202 (2007).

[7] A. F. Kohan et al., Physical Review B 61, 15019 (2000).

[8] C. G. Van de Walle, Physical Review Letters 85, 1012 (2000).

[9] S. Limpijumnong, and S. B. Zhang, Applied Physics Letters 86, 151910 (2005).

[10] J. Hu, and R. G. Gordon, Journal of Applied Physics 71, 880 (1992).

[11] Y. Igasaki, and H. Saito, Journal of Applied Physics 70, 3613 (1991).

[12] A. F. Aktaruzzaman, G. L. Sharma, and L. K. Malhotra, Thin Solid Films 198, 67 (1991).

[13] A. V. Singh et al., Journal of Applied Physics 90, 5661 (2001).

[14] J. N. Duenow et al., J. Vac. Sci. Technol. A 26, 692 (2008).

[15] W. Klysubun et al., AIP Conference Proceedings 879, 860 (2007).

[16] C. G. Van de Walle, and J. Neugebauer, Journal of Applied Physics 95, 3851 (2004).

[17] G. Kresse, and J. Furthmüller, Comput. Mat. Sci. 6, 15 (1996).

[18] G. Kresse, and J. Hafner, Journal of Physics Condensed Matter 6, 8245 (1994).

[19] A. L. Ankudinov et al., Physical Review B 65, 104107 (2002).

[20] A. L. Ankudinov et al., Physical Review B 58, 7565 (1998).

[21] G. Kresse, and D. Joubert, Physical Review B 59, 1758 (1999).

[22] O. Madelung, M. Schulz, and H. Weiss, Numerical Data and Functional Relationships in Science and Technology (SpringerVerlag, Berlin, 1982), Vol. 17.

[23] H. J. Monkhorst, and J. D. Pack, Physical Review B 13, 5188 (1976).

[24] R. P. Feynman, Physical Review 56, 340 (1939).

[25] S. Limpijumnong et al., Appl. Phys. Lett. 90, 103113 (2007).

[26] S. B. Zhang, Journal of Physics: Condensed matter 14, R881 (2002). 
[27] See EPAPS Document No. xxxx for the calculated defect formation energy. This document can be reached via a direct link in the online article's HTML reference section or via the EPAPS homepage

(http://www.aip.org/pubservs/epaps.html).

[28] T.-L. Chan, D. West, and S. B. Zhang, Physical Review Letters 107, 035503. 
Table 1. The growth condition for Al-doped $\mathrm{ZnO}$ thin films. The carrier concentration and mobility of each sample depend on the growth conditions.

\begin{tabular}{cccccc}
\hline \hline $\begin{array}{c}\text { Sample } \\
\text { Name }\end{array}$ & $\begin{array}{c}\mathrm{Al}_{2} \mathrm{O}_{3} \\
\text { Content } \\
(\text { wt. } \%)\end{array}$ & $\begin{array}{c}\text { Sputtering } \\
\text { Gas }\end{array}$ & $\begin{array}{c}\text { Film } \\
\text { Thickness } \\
(\mathrm{nm})\end{array}$ & $\begin{array}{c}\text { Carrier } \\
\text { Conc. } \\
\left(\mathrm{cm}^{-3}\right)\end{array}$ & $\begin{array}{c}\text { Mobility } \\
\left(\mathrm{cm}^{2} \mathrm{~V}^{-1} \mathrm{~s}^{-1}\right)\end{array}$ \\
\hline OP-a/2.0 & 2.0 & $0.3 \% \mathrm{H}_{2} / \mathrm{Ar}$ & 430 & $7.3 \times 10^{20}$ & 25 \\
OP-a/1.0 & 1.0 & $0.3 \% \mathrm{H}_{2} / \mathrm{Ar}$ & 490 & $5.5 \times 10^{20}$ & 32 \\
OP-a/0.5 & 0.5 & $0.3 \% \mathrm{H}_{2} / \mathrm{Ar}$ & 410 & $3.4 \times 10^{20}$ & 36 \\
OP-a/0.1 & 0.1 & $0.3 \% \mathrm{H}_{2} / \mathrm{Ar}$ & 370 & $1.1 \times 10^{20}$ & 52 \\
\hline OP-b/1.0 & 1.0 & $1 \% \mathrm{H}_{2} / \mathrm{Ar}$ & 430 & $5.7 \times 10^{20}$ & 20 \\
OP-a/1.0 & 1.0 & $0.3 \% \mathrm{H}_{2} / \mathrm{Ar}$ & 490 & $5.5 \times 10^{20}$ & 32 \\
OFix/1.0 & 1.0 & $100 \% \mathrm{Ar}$ & 610 & $4.4 \times 10^{20}$ & 29 \\
OR-a/1.0 & 1.0 & $0.3 \% \mathrm{O}_{2} / \mathrm{Ar}$ & 520 & $2.3 \times 10^{19}$ & 0.1 \\
OR-b/1.0 & 1.0 & $0.5 \% \mathrm{O}_{2} / \mathrm{Ar}$ & 480 & $7.3 \times 10^{18}$ & 0.1 \\
\hline \hline
\end{tabular}



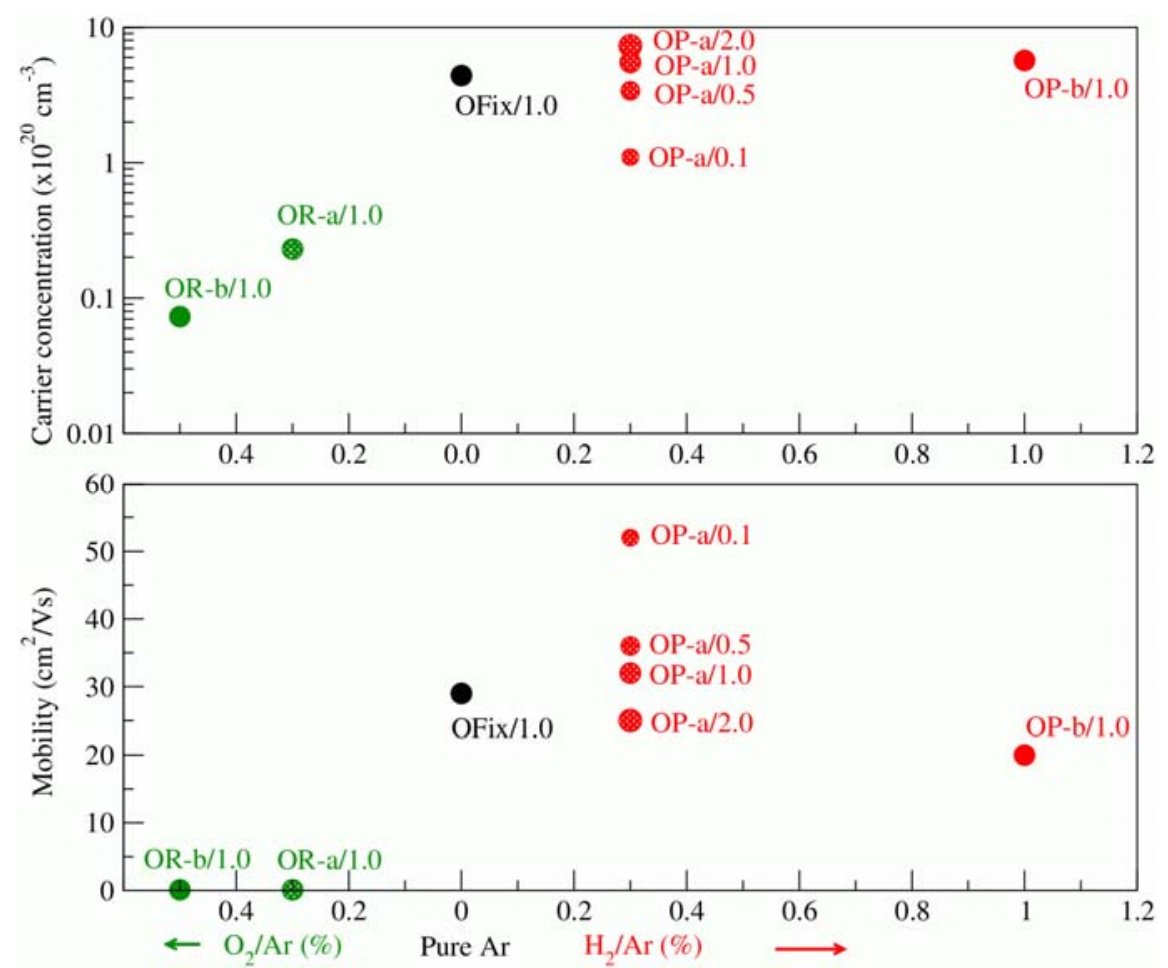

Fig. 1 (Color online) The carrier concentration (top panel) and mobility (bottom panel) of samples grown with different sputtering gas and Al concentrations.

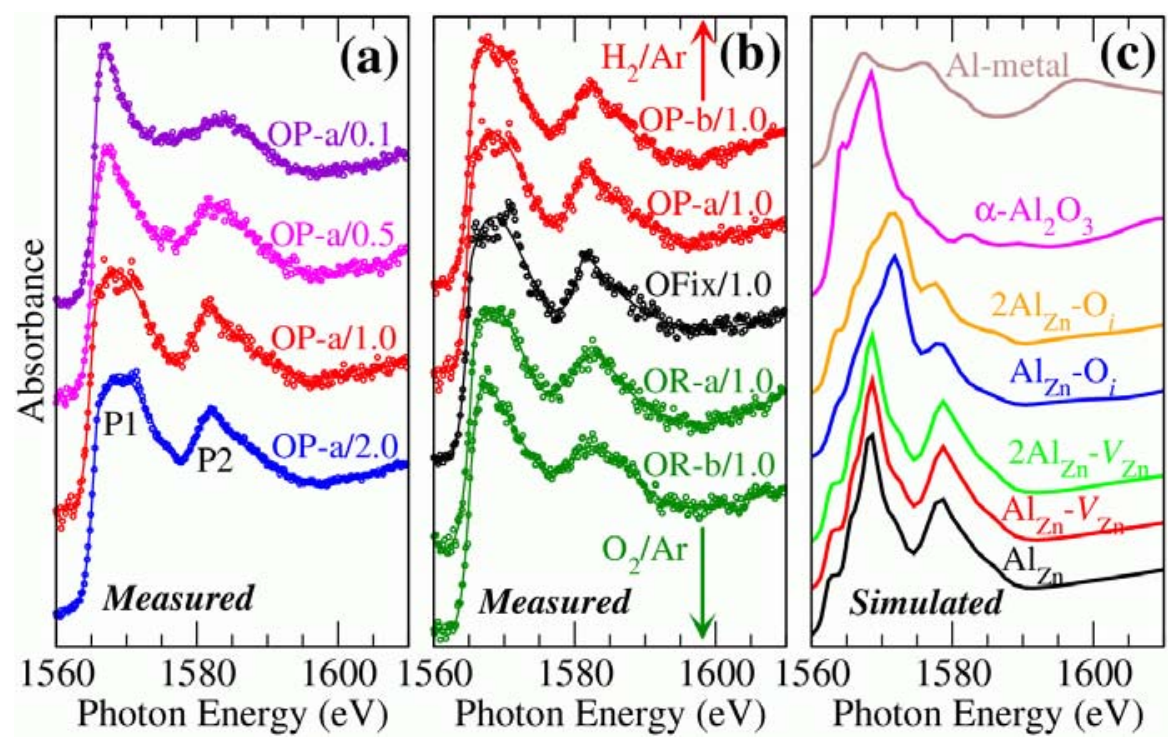

Fig. 2 (Color online) (a) The measured Al $K$-edge XANES spectra of samples grown under $0.3 \% \mathrm{H}_{2} / \mathrm{Ar}$ sputtering gas with varied $\mathrm{Al}$ contents from 0.1 to $2.0 \%$. (b) The spectra of samples with $\mathrm{Al}$ content of $1.0 \%$ grown under different sputtering gas conditions from O-Poor to O-rich. (c) The simulated spectra from different local structure models of Al. 


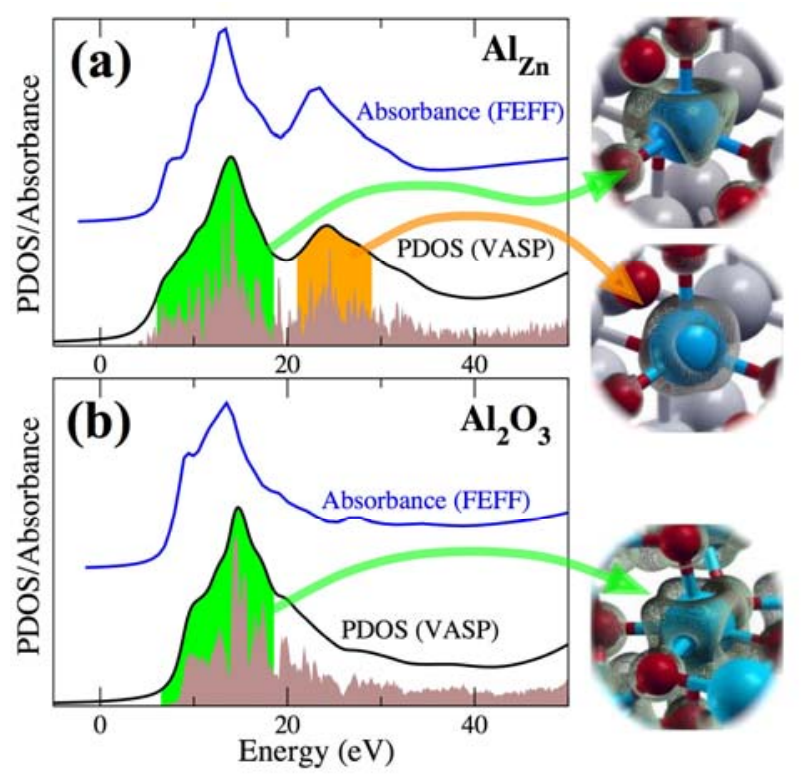

Fig. 3 (Color online) Calculated Al site and angular momentum $(l=1)$ projected partial density of states (PDOS) based on VASP and simulated absorption spectra based on FEFF of (a) $\mathrm{Al}_{\mathrm{Zn}}$ in $\mathrm{ZnO}$ and (b) $\mathrm{Al}$ in $\alpha-\mathrm{Al}_{2} \mathrm{O}_{3}$. PDOSs are broadened (originals showed under each curve) and shown relative to the valence band maximum and the absorbances are shifted for ease of comparison. The electron density associated with the peaks P1 and P2 for $\mathrm{Al}_{\mathrm{Zn}}$ and $\mathrm{P} 1$ for $\mathrm{Al}_{2} \mathrm{O}_{3}$ are shown in the insets. 